\title{
INTERCHANGE I AND GRAMMAR DIMENSIONS I: IS THE NATURAL ORDER OF MORPHEME ACQUISITION TAKEN INTO ACCOUNT IN THE SEQUENCE OF THEIR UNITS?
}

\author{
Mayra Solís Hernández.
}

\begin{abstract}
RESUMEN
Este artículo intenta demostrar que el orden natural de la adquisición de morfemas gramaticales no se tomó en cuenta al hacer la secuencia de las unidades de los libros de texto Interchange I y Grammar Dimensions I. Por esta razón, este trabajo ofrece recomendaciones al respecto para los instructores de inglés que usen estos libros de textos, y además, propone ciertas implicaciones para la enseñanza del inglés como lengua extranjera.
\end{abstract}

\begin{abstract}
This article pretends to demonstrate that the natural order of acquisition of grammatical morphemes is not taken into account in the sequence of units in the textbooks Interchange $I$ and Grammar Dimensions I. Thus, it provides recommendations for English instructors who might use these books. Teaching implications are also provided.
\end{abstract}

Second language acquisition (SLA) is a very complex process which has always puzzled English teachers, and the question "How is a second language acquired?" still intrigues researchers. Many possible answers to this question have been provided throughout time, but investigators continue their search in their attempt to speed up the process and help learners acquire a second or foreign language in the most efficient way. One of the most striking findings in regard to SLA is that the acquisition of certain English grammatical structures proceeds in a predictable order, that is, acquirers learn some structures earlier than others (Dulay and Burt 1974; Bailey, Madden and Krashen 1974).

As English instructors, we might think that the best way to go about in our classes is to present the grammatical structures in the same order they appear in our textbooks. However, most of the time, we notice that our students keep making the same errors, no matter how much we practice and drill certain structures.At times, these students seem to have acquired the patterns because they can use them correctly in drills or memorized dialogues, but they fail to use them appropriately in spontaneous conversations. Perhaps the reason why this situation occurs is that the order of the presentation of the structures is not the natural one, and we are forcing the learners to acquire structures when they are not ready for them. In other words, we are breaking the natural order of morpheme acquisition and working against the acquisition process. 
Conscious of the hard job we, English teachers, have ahead of us, we always look for the best materials and textbooks for our students. However, many times we take for granted that the textbooks that come out to the market will efficiently meet our learners' needs, especially if the authors are well known in the field, and very rarely do we take some time to examine and question some of these materials. Being aware of this fact, the author of this article intends to determine if the textbooks Interchange I by Jack Richards, Jonathan Hull and Susan Proctor and Grammar Dimensions I by Victoria Badalamenti and Carolyn Henner-Stanchina take into account the natural order of acquisition of grammatical morphemes in the sequence of their units. If not, some recommendations and teaching implications will be provided.

\section{Background}

English is perhaps the most investigated language as far as the natural order hypothesis is concerned, and of all the structures of English, morphology seems to be the most studied. There are many studies of acquisition order attempting to determine the order in which learners acquire language structure. In 1977, 1985, Krashen proposed the Natural Order Hypothesis, which states that learners acquire the rules of language in a predictable order, some rules tending to come early and others late. He also argued that this order does not appear to be determined only by formal simplicity, and it is independent of the order in which rules are taught in language classes. However, this is not the first time we have evidence of a natural order of morpheme acquisition because Brown (1973) reported that children acquiring English as a first language tend to acquire certain grammatical morphemes, or functions words, earlier than others. For example, the progressive marker and the plural marker/s/ were among the first acquired, while the third person singular marker /s/ and the possessive /s/ were typically acquired much later, coming anywhere from six months to one year later.

De Villiers and de Villiers (1973) confirmed Brown's longitudinal results cross-sectionally, showing that items that Brown found to be acquired earliest in time were also the ones that children tended to get right more often. In other words, for those morphemes studied, the difficulty order was similar to the acquisition order.

Dulay and Burt (1974) reported that children learning English as a second language also show a natural order for grammatical morphemes, regardless of their first language. These authors looked at accuracy order of eleven morphemes in children's speech, by determining what percentage of times a subject correctly supplied a morpheme in an obligatory context. This accuracy order was assumed to reflect acquisition order. Dulay and Burt came up with a morpheme rank order (MRO), which includes pronoun case (subject and object pronouns), article (a - the), copula (to be), progressive (-ing), plural (-s), auxiliary (be going + verb), regular past, irregular past, long plural (-es), possessive, and third person singular. Dulay and Burt's results have been confirmed by a number of investigators (Kessler and Idar 1977; Fabris 1978; Makino 1980).

Bailey, Madden, and Krashen (1974) reported a natural order for adult subjects, an order quite similar to that seen in child second language acquisition.After having done many empirical research studies of grammatical morpheme acquisition, these authors found that children and adults follow an average order of acquisition of grammatical morphemes (AOAGM) for English as a second language. The AOAGM includes the following sequence of morphemes: progressive, plural, copula, auxiliary, article, irregular past, regular past, third 
person singular, and possessive. Some of the studies confirming the natural order in adults for grammatical morphemes include Andersen (1976), Krashen, Houck, Giunchi, Bode, Birnbaum, and Strei (1977).

Fathman (1975) confirmed the reality of the natural order in child second language acquisition with her test of oral production, the SLOPE test, which probed 20 different structures. Krashen, Sferlazza, Feldman, and Fathman (1976) also confirmed the natural order in adult research using the SLOPE test.

Dulay, Burt and Krashen (1982) stated that language acquisition is a gradual process that can take anywhere from several months to several years. During this time the learner acquires the different structures that make up a language: tense endings, plural markers, negative sentences, complements, and so forth. Learners acquire some of these structures almost immediately; others are acquired later, and still others are acquired only after much natural exposure to the language. Hasbún (1992) did a study with 38 Costa Rican Spanish speaking English majors in two different oral courses. Her investigation aimed at verifying Krashen's natural order hypothesis and to study the effect of formal instruction on the acquisition of the structures measured by the SLOPE test. The hypothesis was verified in both groups. She also concluded that formal instruction affects the level of acquisition of the objectives of the SLOPE test, but not the order in which they are acquired.

Escalante (1994) also conducted a study using the SLOPE test. She studied 25 Costa Rican children learning English in a bilingual school (17 fifth graders and 12 sixth graders). This study determined that the subjects, who had contact with the target language only in the classroom, acquired morphemes exactly in the same order proposed by Krashen in his natural order hypothesis.

\section{Materials Analysis}

This article analyzes the sequence of eleven structures in two textbooks: Interchange Book I and Grammar Dimensions Book I. The former is presently used as a basic textbook in the first-year oral course LM-1001 Basic English I at the School of Modern Languages at the University of Costa Rica. This is the first English course intended for English majors. The latter is a recently published textbook which might be used as a reference book in some English courses at the university level.

Interchange is a multi-level course in English as a second language for young adults and adults. The primary goal of the course is to teach communicative competence, that is, the ability to communicate in English according to the situation, purpose and roles of the participants. Book I, which contains 15 units, is for beginners and takes students from beginner or false beginner to low-intermediate level. In contrast, the philosophy behind the series Grammar Dimensions is that English learners must use grammatical forms accurately, meaningfully, and appropriately. Therefore, this series takes into account all three dimensions of language: syntax / morphology (form), semantics (meaning), and pragmatics (use). Book I, which contains 30 units, deals with basic sentence and subsentence grammatical structures.

This analysis was done using the list of grammatical morphemes provided by Dulay and Burt (1974), called Morpheme Rank Order (MRO). Table 1 shows the MRO and the order in which these same morphemes are presented in Interchange I(I) and in Grammar Dimensions I (GD). 
Table 1

Morpheme Rank Order and order of presentation of morphemes in Interchange and Grammar Dimensions

\begin{tabular}{|c|c|c|}
\hline Dulay \& Burt's & Interchange & Grammar Dimensions \\
\hline MRO & Book I & Book I \\
\hline Pronoun case & Pronoun case & Copula \\
\hline (he - him) & (he) & (be) \\
\hline Article & Copula & Pronoun case \\
\hline (a / the) & (be) & (he) \\
\hline Copula & Article & Article \\
\hline (be) & (a / the) & (a / an) \\
\hline Progressive & Plural & Plural \\
\hline (-ing) & $(-s)$ & $(-s)$ \\
\hline Plural & Long plural & Long plural \\
\hline$(-s)$ & $(-\mathrm{es})$ & $(-\mathrm{es})$ \\
\hline Auxiliary & Possessive & Article \\
\hline (be going to) & ( 's) & (the) \\
\hline Regular past & Pronoun case & Possessive \\
\hline (-ed) & (him) & ( 's) \\
\hline Irregular past & 3rd person singular & 3rd person singular \\
\hline (came / went) & $(-s)$ & $(-\mathrm{s})$ \\
\hline Long plural & Regular past & Pronoun case \\
\hline$(-\mathrm{es})$ & $(-\mathrm{ed})$ & (him) \\
\hline Possessive & Irregular past & Progressive \\
\hline & (came) & (-ing) \\
\hline \multirow{6}{*}{$\begin{array}{l}\text { 3rd person singular } \\
(-\mathrm{s})\end{array}$} & Progressive & Regular past \\
\hline & (-ing) & (-ed) \\
\hline & & Irregular past \\
\hline & & (came) \\
\hline & & Auxiliary \\
\hline & & (going to) \\
\hline
\end{tabular}

As can be observed in Table 1, neither $I$ nor $G D$ follows exactly the same order proposed by Dulay and Burt, and some morphemes are treated differently. For example, pronoun case (subject and object pronouns) is acquired at a very early stage according to Dulay and Burt, and both types of pronouns are acquired at the same time. I and GD present them in separate units as two different structures. $I$ introduces subject pronouns in the first unit and object pronouns three units later. $G D$ treats pronoun case in a similar manner: first subject pronouns and later object pronouns.

Dulay and Burt propose that plural formation is acquired in two different stages. Students first learn the plural forms that take the morpheme /-s/ (cars, boys), and later on they will learn those forms that require /-es/ (dishes, churches). Neither textbook treats plural formation as two different instances, and both $I$ and $G D$ present the two morphemes in one unit. That is, students face the two structures at the same time, in only one step. 
In regard to articles (a / the) and the copula "be", we can see that these are morphemes acquired very early in the process. Both textbooks seem to follow this principle because these structures are introduced in the first units of the textbooks. However, $G D$ goes against the MRO and separates indefinite pronouns from definite ones.

Apparently, regular and irregular past tense forms are learned one after the other according to the MRO. However, $I$ and $G D$ treat both forms as only one process and they are presented in one same unit. Taking a look at some exercises in $I$, we observe that this book mixes both forms (regular and irregular) even from the first exercises. In this respect, GD keeps closer to the MRO because the student is introduced to regular verbs first and later to irregular ones. After this, there are some tasks where the two types of verbs are combined.

A striking fact in $I$ is that the structure "be going to" is completely absent; there is not an instance of this morpheme in the whole textbook even though this morpheme is the sixth one in the MRO. Probably, the authors of $I$ consider that this structure is not very necessary at this beginning level. Similarly, the authors of $G D$ might have considered that "be going to" is not a very important or frequent morpheme in English because it is not introduced in the book until Unit 23.

Possessive forms, in contrast to "be going to", are acquired later according to Dulay and Burt, but surprisingly enough, they are presented very early in I (Unit 3). The same holds true for $G D$ because we find possessive forms very early in the book.

A surprising fact is that the -ing morpheme is presented very late in $I$ (last unit) and in $G D$, but in the MRO it appears as the fourth morpheme on the list. Another revealing fact is that third person singular is the last acquired morpheme in the MRO, but it is not the last one in $I$ or in $G D$.

Table 2 presents Dulay and Burt's MRO and the number of each unit where these morphemes are introduced for the first time.

Table 2

Order of morphemes by unit number in I and GD

\section{MRO}

Pronoun case

(he - him)

Article (a - the)

Copula (be)

Progressive (-ing)

Plural (-s)

Aux (going to)

Regular past

Irregular past

Long plural (-es)

Possessive ('s)

3rd person singular

\section{Interchange}

Unit 1 (he)

Unit 4 (him)

Unit 2

Unit 1

Unit 9

Unit 3

NI*

Unit 7

Unit 7

Unit 3

Unit 3

Unit 5

\section{Grammar dimensions}

Unit 1(he)

Unit 15 (him)

Unit 4

Unit 1

Unit 18

Unit 4

Unit 23

Unit 20

Unit 20

Unit 4

Unit 6

Unit 11

* NI: This structure is not included in Interchange I. 
Table 2 shows that apparently the MRO was not followed in these textbooks because the unit numbers do not follow an increasing order; quite the opposite, they are completely mixed and present a random order.

To illustrate the above idea more clearly, two figures are shown. Figure 1 presents the sequence of morphemes observed in $I$, and Figure 2 shows the sequence found in $G D$.

Figure 1

Sequence of morphemes observed in Interchange I

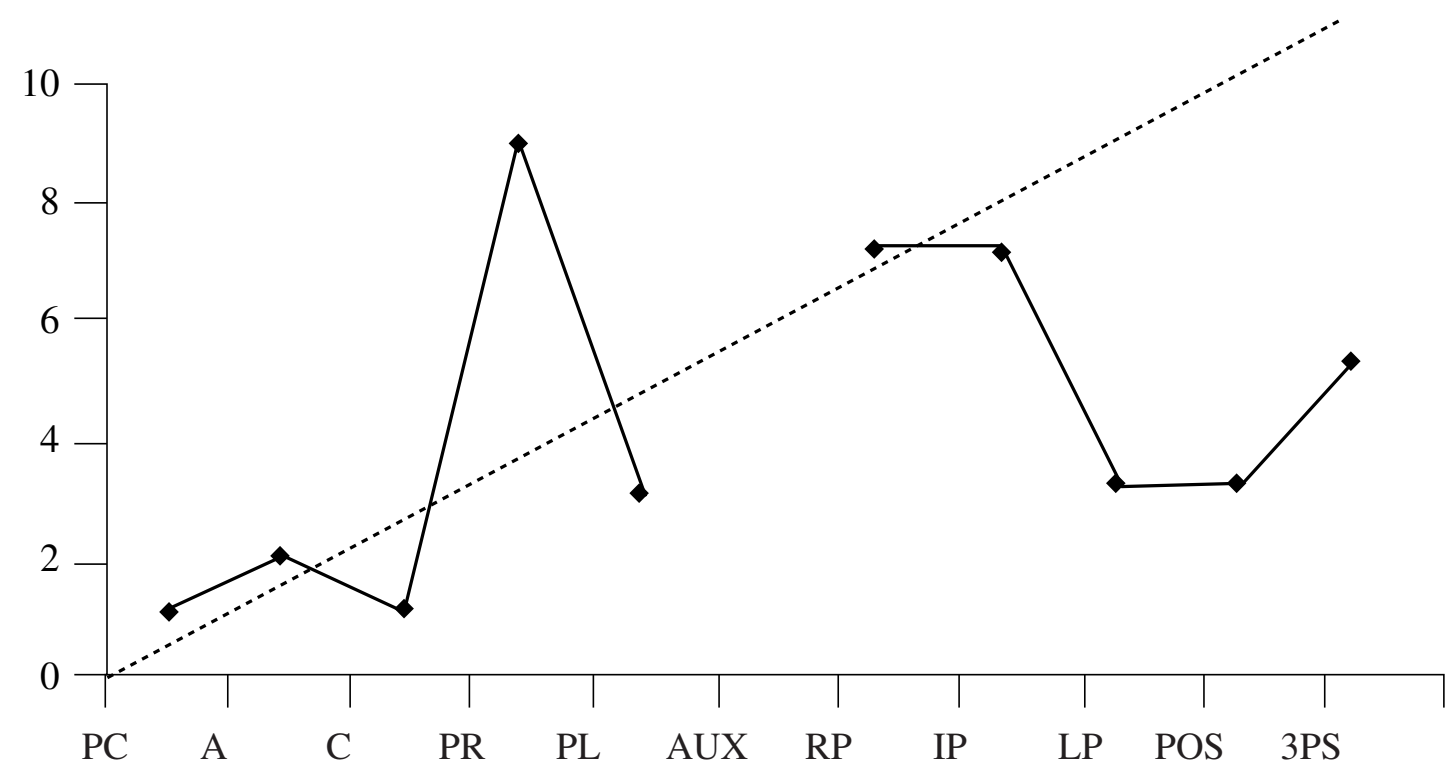

PC: Pronoun case

RP: Regular past

A: Article

IP: Irregular past

C: Copula

PR: Progressive

LP: $\quad$ Long plural

PL: Plural

POS: Possessive

AUX: Auxiliary

3PS: 3rd person singular

Figure 1 shows that seven out of eleven morphemes in Interchange fall below the natural line, which stresses the "learning pressure" built into the book; two are close to natural and the other two are "stress free" for the students. 
Figure 2

Sequence of morphemes observed in Grammar Dimensions I

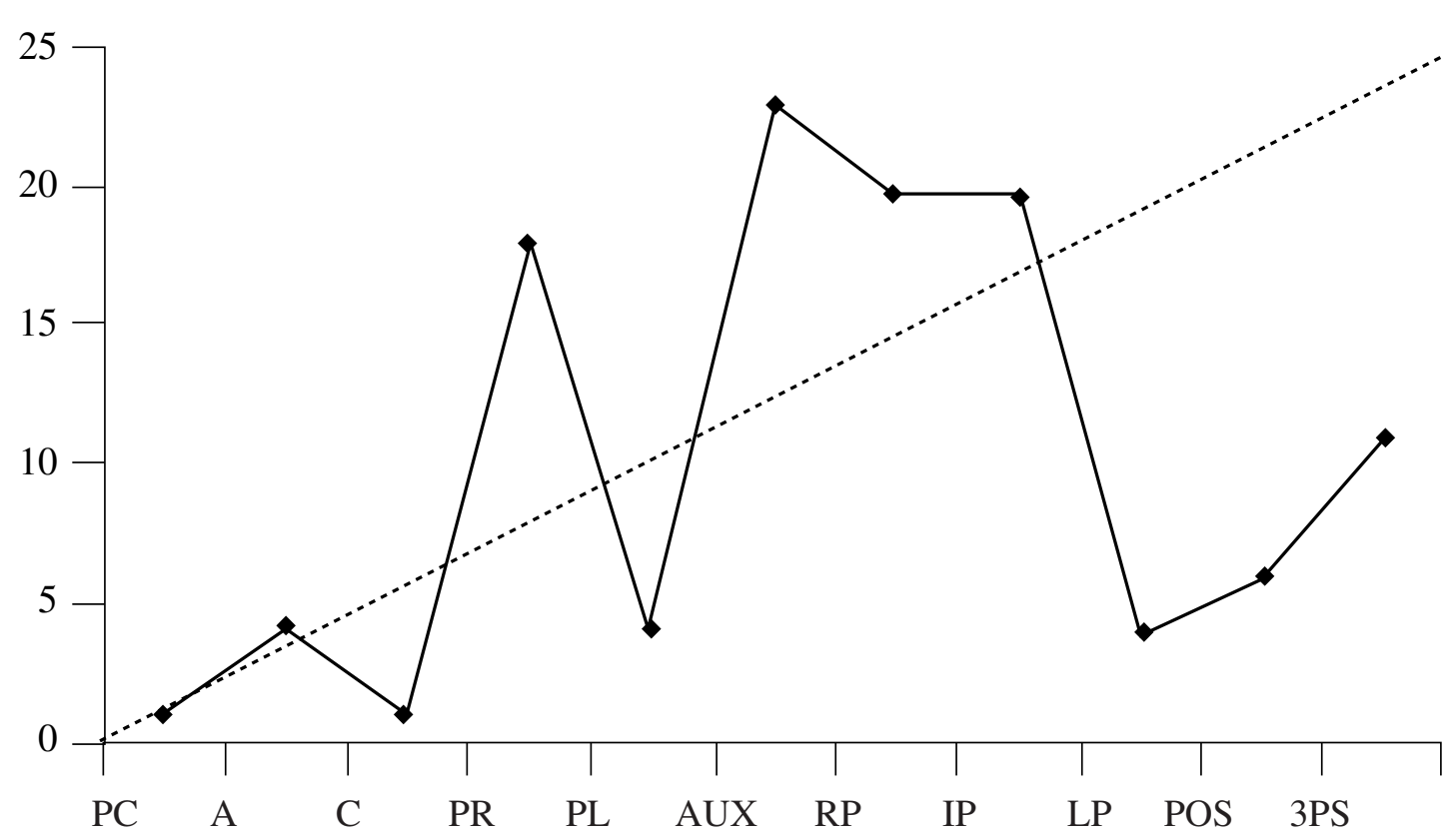

PC: Pronoun case

RP: $\quad$ Regular past

A: Article

IP: Irregular past

C: Copula

PR: Progressive

LP: $\quad$ Long plural

PL: Plural

POS: Possessive

AUX: Auxiliary

3PS: 3rd person singular

In Grammar Dimensions I, only one morpheme is close to natural; five others build pressure on the learner, and the other five should be learned rather early since students have been ready for them for a while. According to Figure 1 and Figure 2, apparently, the MRO was not taken into account in the sequence of structures of $I$ or $G D$.

\section{Discussion}

The present study reveals that probably the order of presentation of structures in some textbooks, at least in the two analyzed here, is not the appropriate one for an efficient learningteaching process. Hence, it is the language teacher's responsibility to study textbooks and decide which structures should be taught first and which later because this order might have a significant effect on students' morpheme acquisition. 
A salient aspect in this regard is that subject pronouns and object pronouns should be taught as one morpheme during the course, and not as two separate structures as they are usually presented in textbooks. Most teachers introduce subject pronouns very early in the process and wait for a long time before introducing object pronouns. These teachers probably think that objective case is a more complex structure and that it should be taught after students have acquired some other structures. Unfortunately, this long wait might go against the learning process according to Dulay and Burt's MRO.

Another striking idea which has been highlighted in this study is that the articles "a" and "the" should be presented as a general category and not as two different instances. Erroneously, both $I$ and $G D$ treat indefinite and definite articles this way. Students might miss the relationship between the two types of articles if they are introduced as two separate morphemes. From my teaching experience I can assure that many of my students acquire the indefinite article pretty soon, but they fail to use the article "the" appropriately, even after having done a lot of practice on its use. Perhaps the way of presenting articles (indefinite first and definite later) is not the most appropriate one and students do not perceive the relationships correctly.

Since neither $I$ nor $G D$ strictly follows the MRO, perhaps a good way to face this weakness would be to change the order of presentation of units and follow the sequence shown in Table 2 for each textbook (second and third columns).

\section{Teaching Implications}

This study presents four teaching implications. First, the contents of the course LM1001 should be modified to include the structure "be going to". Since this structure is one of the earliest acquired according to Dulay and Burt's MRO (the sixth one), the teacher should take advantage of this fact and include it in one of the first units of Interchange I. It seems rather surprising that after taking this first course, students do not know how to use the future tense.

Second, English students should be taught definite and indefinite articles as only one morpheme, so that they can realize that there is a close relationship between "a" and "the". Obviously, the differences in meaning and use between the two forms should be pointed out, but instructors should not wait until students acquire the indefinite article to present the definite one.Besides, articles should be taught very early in the language learning process because this morpheme is acquired early according to the MRO.

Third, English teachers should not feel frustrated when students keep making mistakes on the third person singular. On the contrary, instructors should be aware that learners acquire this structure late in their language acquisition process and provide them with more extensive practice. Also, if teachers are conscious that it takes students longer to acquire this morpheme, they can be more patient and have a more positive attitude toward the learning process.

Finally, perhaps the most useful implication here is that English teachers should present both nominative and objective cases as only one morpheme and as the first structure to be acquired by learners. According to the MRO, it seems that beginning English learners are ready to learn both subject and object pronouns very early. 


\section{Suggestions for Further Research}

A limitation of this study is that the MRO was the result of Dulay and Burt's reasearch with children learning English, and both Interchange and Grammar Dimensions are designed for adults and not for children. The author of the present study assumes here that children and adults follow the same sequence of morpheme acquisition.Keeping this in mind, it would be interesting to carry out a similar study to this one using the AOAGM and compare both results.

Another possible related research project could be an experiment with two groups. A control group would use Interchange as it is, and an experimental group would use it but changing the order of presentation of morphemes to meet the sequence in the MRO. The results would be compared to confirm validy of the MRO.

Finally, the sequence of morphemes of the SLOPE test could be used to check the order of structures in both Interchange and Grammar Dimensions, and the results here could be compared to the ones obtained in the present study.

\section{Bibliography}

Andersen, R. 1976. "A functional acquisition hierarchy study in Puerto Rico." Paper presented at the annual TESOL conference, New York.

Badalamenti, V. and C. Henner-Stanchina. 1993. Grammar Dimensions Book I. Boston: Heinle \& Heinle Publishers.

Bailey, N., C. Madden and S. Krashen. 1974. "Is there a 'natural sequence' in adult second language learning?" Language Learning. 21: 235-243.

Brown, R. 1973. A First Language. Cambridge: Harvard Press.

Dulay, H. and M. Burt. 1974. "Natural sequences in child second language acquisition." Language Learning. 24: 37-53.

Dulay, H., M. Burt and S. Krashen. 1982. Language Two. New York: Oxford University Press.

De Villiers, P. and J. de Villiers. 1973. "A cross-sectional study of the acquisition of grammatical morphemes in child speech." Journal of Psycholinguistic Research. 2: 267-78.

Escalante, P. 1994. "Orden de adquisición de diferentes morfemas en un grupo de niños estudiantes de inglés como lengua extranjera." Káñina. XVIII (1): 105-11.

Fabris, M. 1978. "The acquisition of English grammatical functors by child second language learners." TESOL Quarterly. 12: 482. 
Fathman, A. 1975. "The relationship between age and second language productive ability." Language Learning. 25: 245-66.

Hasbún, L. 1992. "Verificación de las secuencias naturales en la adquisición de morfemas en el inglés como lengua extranjera." Revista de Educación. 16 (1): 89-99.

Kessler, C. and I. Idar. 1977. "The acquisition of English syntactic structures by a Vietnamese child." Paper presented at the Los Angeles Second Language Acquisition Forum, UCLA.

Krashen, S. 1982. Principles and Practice in Second Language Acquisition. New York: Pergamon Press.

Krashen, S., N. Houck, P. Giunchi, S. Bode, R. Birnbaum and J. Strei. 1977. "Difficulty order for grammatical morphemes for adult second language performers using free speech." TESOL Quarterly. 11: 338-41.

Krashen, S., V. Sferlazza, L. Feldman and A. Fathman. 1976. "Adult performance on the Slope test: more evidence for a natural sequence in adult second language acquisition." Language Learning. 26: 145-51.

Makino, T. 1980. Acquisition Order of English Morphemes by Japanese Adolescents. Tokyo: Shinozaki Shorin Press.

Richards, J., J. Hull and S. Proctor. 1990. Interchange Book I. Cambridge: Cambridge University Press. 